\title{
Hormonal therapy in metastatic prostate cancer: current perspectives and controversies
}

\author{
Manish Garg, Vishwajeet Singh, Manoj Kumar, Satya Narayan Sankhwar \\ Department of Urology, King George Medical University, Lucknow, India
}

\begin{abstract}
Ever since the introduction of androgen deprivation therapy (ADT) in prostate cancer, various controversial aspects of hormonal therapy have come to light. There has been tremendous progress in this area, marked by several important developments in the availability of various new androgen-suppressing agents and refinements to the existing therapies. Parallel to these developments, various more debatable aspects have arisen in the use of these therapies with regards to their negative impact on quality of life parameters. Various modifications in these hormonal agents, their doses, and protocols have been tried in different scenarios in order to improve ADT tolerability. As a result, these controversies continue to evolve even with optimal use of the androgen ablation therapy. This review assesses the present status of hormonal therapy in metastatic prostate cancer and specifically deals with those aspects of androgen ablation therapy that are still a subject of debate. In spite of the fact that various trials have been conducted, some of which are still ongoing, the multitude of questions related to the best possible use of these hormonal agents have still not been answered. Treatment guidelines concerning these issues are continuing to evolve as progress continues to be made in this field.
\end{abstract}

\footnotetext{
Correspondence: Manish Garg, Department of Urology King George Medical University, Lucknow 226003, India.

Tel. +91-7607333618. E-mail: dr_manugarg@yahoo.co.in

Key words: prostate cancer, androgen ablation therapy, intermittent hormonal therapy, combined androgen blockage, antiandrogens.

Contributions: all the Authors made substantial contributions to study conception and design, acquisition or analysis and interpretation of data, drafting or critically revising the article for important intellectual content, and approving the final version to be published.

Conflict of interests: the authors declare no potential conflict of interests.

Received for publication: 10 June 2013

Revision received: 5 September 2013.

Accepted for publication: 5 September 2013.

This work is licensed under a Creative Commons Attribution NonCommercial 3.0 License (CC BY-NC 3.0).

(C) Copyright M. Garg et al., 2013

Licensee PAGEPress, Italy

Oncology Reviews 2013; 7:e6

doi:10.4081/oncol.2013.e6
}

\section{Introduction}

Prostate cancer is the most prevalent cancer worldwide in men and is the leading cause of death in Western countries. It is usually a hormone-dependent malignancy and most of the men with metastatic disease respond to various forms of androgen deprivation therapy (ADT). Rapid and dramatic beneficial clinical effects are seen with $\mathrm{ADT}^{1}$ and it has been regarded as a first-line treatment option in men with metastatic prostate cancer for many decades. ${ }^{2}$

The use of ADT in the management of prostate cancer has been a matter of debate since the time of its introduction by Huggins and Hodges in $1941^{1}$ and to clarify these issues several randomized trials have been carried out. As the androgen ablation therapy can have a negative impact on quality of life (QoL) due to associated side-effects, various strategies to manage these problems are taken into consideration. ${ }^{3,4}$ Due to the involvement of new therapeutic options, use of prostate-specific antigen (PSA) monitoring and the development of new medications such as gonadotropin-releasing hormone (GnRH) analogs and antagonists, the management of androgen-sensitive metastatic and/or recurrent prostate cancer continues to evolve, as do the associated controversial issues. ${ }^{5}$ At present, a myriad of options are available for androgen ablation therapy in metastatic cancer disease $^{6}$ which are no doubt of immense help but also create a dilemma in the approach to therapy.

\section{Review methodology}

A systemic review search was conducted using the search words hormonal therapy in prostate cancer AND treatment of prostate cancer AND metastatic prostate cancer AND GnRH agonists and antagonists AND antiandrogens to identify published articles on the present role of androgen ablation therapy in prostate cancer. The term intermittent androgen therapy AND combined androgen blockage AND maximum androgen blockage AND early androgen therapy AND bicalutamide monotherapy were also searched in PubMed. In addition, the Related Articles search option on PubMed and references of relevant articles were also looked for. At the end of the literature search, the most relevant articles specifically dealing with controversial aspects of androgen ablation therapy for hormone-sensitive prostate cancer were selected for discussion.

\section{Standard initial treatment: gonadotropin- releasing hormone agonists or antagonists?}

There are various options currently available by which androgen deprivation can be achieved, each with there own advantages and dis- 
advantages. Due to the earlier detection of prostate cancer at a relatively young age, and since these patients are sexually and physically active, the issues of quality of life and related aspects have become of the utmost important. ${ }^{7}$ Historically, bilateral orchidectomy was regarded to be the first and oldest method of permanent castration, while medical therapy using diethylstilbestrol (DES) was the first reversible method. ${ }^{8-11}$

However, the majority of men prefer not to undergo surgical castration because of the considerable psychological trauma involved, with an irreversible impact on libido and erectile function. ${ }^{12,13}$ Perhaps this method is less preferable nowadays, but some cohorts of patients still favored this approach due to the benefits in terms of cost and it being a convenient one-off definitive therapy. ${ }^{14}$

There is a general consensus that GnRH agonists achieve and maintain the serum testosterone levels equivalent to that of surgical castration. ${ }^{15-18}$ Both bilateral orchidectomy or GnRH agonists are the firstline therapeutic options in metastatic prostate cancer as recommended by the National Comprehensive Cancer Network (NCCN) 2009 and American Society of Clinical Oncology (ASCO) 2007 guidelines. ${ }^{19,20}$

For the moment, gonadotropin-releasing hormone agonists have become the preferred treatment option among the various therapeutic armamentariums for ADT. GnRH agonists are recommended as the standard of care because these agents: i) have reversible drug effects as they can be discontinued and thus can be used as Intermittent Androgen Deprivation (IAD) therapy; ii) avoid the adverse effects related to orchidectomy; iii) avoid diethylstilbestrol-related cardiotoxicity; iv) have equivalent oncological efficacy to other available options. ${ }^{15,21,22}$

\section{Gonadotropin-releasing hormone antagonists: a new role}

Data from a phase II study by Tomera et al..$^{23}$ concluded that, in contrast to GnRH agonists, there was a fast reduction in testosterone level (and PSA levels) within ten days with the use of GnRH antagonist in patients with prostate cancer. No testosterone surge or clinical flare was observed and, on discontinuing the therapy, quick recovery in testosterone levels was measured.

In a recent prospective randomized phase III trial, ${ }^{24}$ either degarelix (GnRH antagonist) or leuprolide (GnRH agonist) was randomly given for 12 months to 610 men diagnosed with prostate cancer. At the end of the trial period, degarelix was found to be equivalent and not inferior to leuprolide: $97.2 \%$ of patients in the degarelix group and $96.4 \%$ in the leuprolide group achieved testosterone suppression to levels of 0.5 $\mathrm{ng} / \mathrm{mL}$ or under from Days 28 to 364 .

Other randomized phase III studies have been published reporting use of abarelix in advanced PCa. ${ }^{25-27} \mathrm{~A}$ European trial compared goserelin/bicalutamide with abarelix while US studies compared abarelix with leuprolide alone or with bicalutamide over three and six months, respectively. Abarelix not only achieved but also maintained the castration effect equivalent to that of comparator groups for three or six months in all these trials ${ }^{26}$ with more rapid testosterone suppression to castrate levels by abarelix without any testosterone surge.

In phase III trials, abarelix displayed almost equivalent incidence of adverse effects and safety prolife to GnRH agonists or anti-androgen. ${ }^{25,26,28}$ However, $1.1 \%$ (15 of 1397) of prostate cancer patients experienced immediate-onset systemic allergic reactions in the abarelix group ${ }^{29}$ with the possibility of an increased QT interval. ${ }^{30}$

GnRH antagonists uniquely benefit patients in whom surgical castration is not appropriate and who have the following risk factors: i) risk of metastatic neurological manifestation; ii) bladder outlet or ureteral obstruction due to metastatic disease or local encroachment; iii) skeletal metastases with severe bone pain not responding to narcotic analgesia use. ${ }^{31} \mathrm{At}$ present, $\mathrm{GnRH}$ agonists are the mainstay of treatment for advanced prostate cancer according to the European Association of Urology (EAU) guidelines. ${ }^{21}$ Recently, GnRH antagonists have emerged as new effective androgen ablation agents. Clinical experience with these drugs suggests possible benefits over GnRH agonists related to their mechanism of action and they may be considered as an alternative first-line treatment option for metastatic prostate cancer in the near future. ${ }^{32,33}$ Also, these new novels agents are able to achieve androgen suppression with serum testosterone levels consistently lower than $20 \mathrm{ng} / \mathrm{dL}$, equivalent to that of surgical orchidectomy, to optimize the prostate cancer disease-specific outcomes. ${ }^{34}$ Nevertheless, it is important that practitioner and patient should discuss in detail the best possible option for the benefit of the individual.

\section{Antiandrogens as monotherapy: equally effec- tive or not?}

Castration-based approaches for androgen ablation are not without adverse effects and can sometimes severely impair quality of life. Up till now, the antiandrogens have usually been used as an additional drug in combined androgen blockage (CAB) regime along with other castration approaches. Because of their potential beneficial effects of maintaining quality of life as regards to libido, potency, bone mineralization and gonadal function, $, 35,36$ there is an obvious tendency to use antiandrogens as monotherapeutic agents in metastatic prostate cancer, though mild breast pain and gynecomastia are common adverse effects of these agents in $70-80 \%$ patients. ${ }^{37}$

There are two types of antiandrogens: steroidal, e.g. cyproterone acetate (CPA), and non-steroidal (bicalutamide, flutamide, nilutamide) ${ }^{38,39}$ In the management of advanced prostate cancer, the clinical role of the non-steroidal antiandrogens has been studied in many different scenarios and this is still the subject of intense ongoing debate in the urology literature. ${ }^{40}$

However, in clinical studies, no significant differences in tumor response rate or disease-specific survival were found between CPA and any other form of androgen deprivation, ${ }^{41}$ while CPA induces severe dose-dependent cardiovascular complications in approximately $10 \%$ of patients. With the availability of safer drugs, therefore, the use of the CPA as monotherapy should not be acceptable. .2, $43^{2}$

Although flutamide was the first non-steroidal antiandrogen to be widely used as $\mathrm{CAB}$, its use as a monotherapy in phase III trials for metastatic prostate cancer has not been extensively studied. ${ }^{42,44}$ After reviewing these trials, Boccardo et al. found no significant differences in response rates or duration. ${ }^{45}$ The efficacy of flutamide with DES at $3 \mathrm{mg} /$ day was compared in a double-blind randomized study ${ }^{46}$ and DES produced significantly longer overall survival than flutamide (43.2 $\mathrm{vs}$ 28.5 months).

No randomized study of the use of nilutamide as monotherapy or comparative trials wih any other hormonal therapy have been conducted, except for a small study in which, although there was a $91 \%$ response rate, this was less than that achieved when nilutamide was used in CAB. ${ }^{47}$ There was a higher incidence of adverse effects in the form of visual problems (adverse light-dark adaptation) in 31\% of study subjects, therefore larger trials using nilutamide as monotherapy were discouraged. ${ }^{39,48}$

A study by McLeod $^{49}$ suggests that although the 3 non-steroidal antiandrogens could not be compared directly in terms of quality of life, available evidence suggests that, in comparison to nilutamide and flutamide, bicalutamide has a more favorable tolerability and safety pro- 
file. Bicalutamide as monotherapy has been most extensively studied among the available non-steroidal antiandrogens. ${ }^{39}$ Although in the early comparative trials using bicalutamide at doses of $50 \mathrm{mg} /$ day, castration had been found to be superior to bicalutamide monotherapy in terms of survival rate ${ }^{50}$ subsequent trials with bicalutamide at 100 or $150 \mathrm{mg}$ /day revealed equivalent efficacy. ${ }^{51,52}$

Schröder ${ }^{53}$ concluded that among the non-steroidal antiandrogens in M0 (without metastasis) prostate cancer patients, bicalutamide $150 \mathrm{mg}$ were equally effective as castration with significant improvement in both physical capacity and sexual interest. On the contrary, bicalutamide $150 \mathrm{mg}$ was not found to be as effective as castration in M1 (metastatic disease) patients but had symptomatic and quality of life benefits. Tyrrell and co-workers ${ }^{51}$ compared bicalutamide monotherapy (150 mg daily) with castration as treatment for both metastatic and locally advanced non-metastatic prostate cancer $(n=1453)$. Bicalutamide monotherapy was as effective as castration in nonmetastatic patients, but in the M1 subgroup a small survival advantage was found in the castration group. Thus, after adequate patient counseling and discussion of the various treatment options, bicalutamide monotherapy may be employed in relatively younger patients who are sexually active with locally advanced disease. Bicalutamide monotherapy may also be given in selected prostate cancer patients with metastatic disease. But the clinical benefits remain marginal in metastatic cancer and, therefore, bicalutamide monotherapy alone is still not considered as recommended standard of care. Although antiandrogen agents are extremely effective in the blockade of GnRH-induced flare, ${ }^{19}$ these agents have not yet been approved by the US Food and Drug Administration (FDA) for monotherapy. According to the American Society of Clinical Oncology, although steroidal antiandrogens should not be offered as monotherapy, non-steroidal antiandrogen may be discussed as an alternative to ADT. ${ }^{19}$ In men with a high disease burden (PSA values $>400 \mathrm{ng} / \mathrm{mL}$ ), castration definitely remains superior to antiandrogen monotherapy. ${ }^{6,54}$

\section{Intermittent hormonal therapy: do we have a consensus?}

It has been found that over a period of months or years nearly all prostate cancer patients treated with hormone therapy ultimately become resistant to it. The potential advantages of intermittent androgen deprivation (IAD) over continuous ADT are: i) improved quality of life; ii) prolonged period of androgen dependence; iii) reduced incidence of side effects such as physiological changes associated with castration; iv) decrease in overall cost of treatment. ${ }^{55}$

Several studies have been conducted to investigate the role of IAD as an alternative to continuous hormonal therapy. ${ }^{56}$ In a randomized trial of 335 patients with advanced prostate cancer, Miller et al. ${ }^{57}$ found equivalent survival (51.4 vs 53.8 months; $\mathrm{P}=0.658$ ) in intermittent or continuous arms, with an off-treatment period of over $40 \%$ of total duration of study in the intermittent arm. In another trial by Langenhuijsen et al., ${ }^{58} 193$ patients were randomized to receive either intermittent or continuous therapy, and after a mean follow up of 34 months, no difference in survival was observed. Calais et al. ${ }^{59}$ conducted a larger trial in which, after randomization, continuous ADT was given in 312 men while 314 patients received intermittent ADT. There were fewer prostate cancer deaths ( 84 vs 106 ) but more cardiovascular deaths (52 vs 41) in the continuous arm as compared to the intermittent arm; however, there was an equivalent number of overall deaths (169 vs 170) in both the groups with a median follow-up period of 51 months from randomization.

Intermittent androgen therapy produces better overall survival and improves outcome by hampering hormonal resistance and delaying its onset, as demonstrated in laboratory studies, ${ }^{60}$ although no clinical data are available at present to confirm this assumption. But there is sufficient phase II evidence that, in terms of time to progression and overall survival, IAD is non-inferior to continuous androgen ablation, and as regards to sexual function, there is growing evidence to suggest that IAD offers significant quality of life benefits, at least during the off-treatment phase.

The results of several pivotal phase III trials have been reported or published recently. As compared to trials in patients of non-metastatic prostate cancer (who have prostate-specific antigen recurrence after definitive local therapy) in which intermittent therapy showed equivalent survival with improved quality of life compared to the continuous therapy, the phase III results are found to be more open to discussion in cases of metastatic prostate cancer disease. ${ }^{61}$

The most recently completed multicentric randomized trial, SWOG $9346,{ }^{62}$ evaluated the overall and disease-specific survival by comparing IAD with continuous therapy in 1535 patients of metastatic prostate cancer with visceral, lymph node or bone metastases and PSA over 5 $\mathrm{ng} / \mathrm{mL}$. Overall survival showed a non-significant improvement in the continuous arm as compared to IAD with a median survival of 5.8 years and 5.1 years, respectively. On sub-analysis, minimal disease group (confined to lymph nodes, axial skeleton or pelvis, $\mathrm{P}=0.034$ ) showed a benefit and the extensive-disease group (ribs, long bones, or visceral involvement) showed no benefit. In the minimal disease group, IAD and MAB groups showed a median overall survival of 5.2 years and 7.1 years, respectively. The study demonstrated that in that setting intermittent therapy was found to be inferior but the interpretation of SWOG 9346 is debatable and fraught with controversies that need further discussion.

According to the EAU guidelines, ${ }^{63}$ the status of intermittent androgen suppression should not be regarded as investigational and can currently be widely offered to patients in various clinical settings of prostate cancer.

The UK National Institute for Health and Clinical Excellence (NICE) ${ }^{64}$ recommends that, provided patients are aware of the therapy's unproven status, in men with newly diagnosed or relapsing metastatic cancer, intermittent therapy can be used as a first-line hormonal therapy option. However, the intermittent therapy option still has not been acknowledged in the American Urological Association (AUA) treatment guidelines. ${ }^{65}$

Nevertheless, if intermittent therapy has to be considered, several points are clear: ${ }^{21}$ i) the initial (induction) cycle of IAD therapy must last between 6 and 9 months; ii) treatment is stopped if metastatic or relapsing patients achieved good PSA response (PSA level $<4 \mathrm{ng} / \mathrm{mL}$ or $0.5 \mathrm{ng} / \mathrm{mL}$, respectively); iii) treatment is resumed when there is either clinical progression or the PSA value rises above $4 \mathrm{ng} / \mathrm{mL}$ in nonmetastatic and $10-15 \mathrm{ng} / \mathrm{mL}$ in metastatic situations; iv) a follow-up procedure must be strictly applied which requires a clinical examination to be carried out every 3-6 months, and PSA should be measured at the same time interval, preferably at the same laboratory.

In conclusion, the results of phase III trials established that IAD offers better quality of life and fewer side effects, in addition to noninferior survival. Also, there is evidence that it results in less toxicity along with the advantage of an equal or longer time to development of castration resistance. ${ }^{66}$ Given the lack of evidence of any long-term effectiveness, intermittent androgen withdrawal therapy may be offered to patients of prostate cancer with metastatic disease. ${ }^{64}$ The benefits it offers to prostate cancer patients warrant its widespread utilization. 


\section{Role of combined androgen blockage: still a dilemma}

The continued release of androgens may occur at low levels from adrenals despite castration therapy. ${ }^{67}$ Androgens generated from an adrenal source can be neutralized by combining one of the antiandrogens to castration and this forms the rationale for combined androgen blockage (CAB) therapy. Various trials have already been conducted in the past to evaluate the efficacy of $\mathrm{CAB}$ and these confirmed an important survival advantage of CAB therapy. ${ }^{68-70}$

A total 8275 men, among whom $88 \%$ had metastatic disease and $12 \%$ had locally advanced prostate cancer, were included in a meta-analysis study of 27 randomized trials performed by The Prostate Cancer Trialists' Collaborative Group. ${ }^{71}$ The 5 -year survival rate was $25.4 \%$ with $\mathrm{CAB}$ and $23.6 \%$ with androgen suppression alone but the difference was not statistically significant. The results for cyproterone acetate appeared slightly unfavorable to $\mathrm{CAB}$, whereas those for nilutamide and flutamide appeared slightly favorable. The analysis concluded that, in advanced prostate cancer, there was an approximately 2-3\% improvement in the 5-year survival rate with the addition of the antiandrogen to androgen suppression.

A meta-analysis by Schmitt et al. ${ }^{72}$ concluded that there was an improvement in progression-free survival at one year and at 5 years, and a $5 \%$ improvement ( $30 \%$ vs $25 \%$ ) in overall survival with CAB.

Recently, a double-blind, multicenter trial was reported by Akaza et $a l .{ }^{73}$ comparing castration versus $\mathrm{CAB}$ using the antiandrogen bicalutamide. Overall deaths with $\mathrm{CAB}$ were fewer than with $\mathrm{GnRH}$ monotherapy at a median follow up of 5.2 years with no reduction in tolerability. The $\mathrm{CAB}$ had a 5 -year overall survival rate of $75.3 \%$ compared to $63.4 \%$ for GnRH-agonist.

In contrast, in a meta-analysis study by Samson et al., no statistically significant difference in survival was found on comparing $\mathrm{CAB}$ with monotherapy, whereas withdrawal due to adverse effects were more common in the CAB arm. ${ }^{74}$ Moinpour evaluated quality of life parameters in patients receiving monotherapy compared with CAB. ${ }^{75}$ Data were collected on different primary parameters including treatmentspecific symptoms, physical functioning, and emotional functioning. Cross-sectional analyses reported significant differences favoring monotherapy in two parameters: increased diarrhea $(\mathrm{P}=0.001)$ and worse emotional functioning $(\mathrm{P}<0.003)$. The remaining $3 \mathrm{QoL}$ parameters (gas pain, body image, and physical functioning) also favored the monotherapy group, although statistically these parameters were not found to be as significant. From the most recent systematic reviews and meta-analyses, it appears that at a 5 -year follow up, CAB provides a small but statistically significant survival advantage $(<5 \%)$ when compared with GnRH monotherapy. ${ }^{76,77}$ Based on critical review studies, Gerald concluded that MAB offers the longest duration of overall survival and should be an option for men with metastatic disease. ${ }^{78}$ Based on the results of analytical research and a randomized clinical trial, it was recommended to give consideration to maximum androgen blockage using bicalutamide. ${ }^{19,68,72}$

$\mathrm{CAB}$ definitely reduced the risk of death compared with castration alone as demonstrated by these studies. But it is not clear if this small advantage is beneficial since $\mathrm{CAB}$ also adversely affects the QoL parameters, especially in the areas of sexuality and cognitive functions. ${ }^{79}$ Several studies even suggested that CAB with a combination of orchidectomy and antiandrogen did not improve overall survival, whereas the use of LHRH analog with antiandrogen had a positive impact. ${ }^{66}$ So far, studies on $\mathrm{CAB}$ have yielded conflicting results and it remains a subject of debate. As evidence in literature shows only a modest survival benefit, and also considering its high cost and adverse effect profile, for the moment $\mathrm{CAB}$ is still an option but not a standard form of first-line therapy for prostate cancer patients, ${ }^{80}$ although patients are commonly prescribed a combination therapy in general clinical practice. ${ }^{81}$ There is a definite need for further randomized controlled trials to evaluate the role of combined androgen blockage and whether it should be started early during the course of the disease or should be given on disease progression with monotherapy. ${ }^{82,83}$

\section{$5 \alpha$-reductase inhibitors: blocking androgen receptor axis}

It is known that androgens play an essential role in prostate growth and development as well as in the prostate cancer pathogenesis. Types 1 and $25 \alpha$-reductase enzymes transform testosterone to dihydrotestosterone (the primary prostatic androgen). Thus, $5 \alpha$-reductase inhibitors (5-ARIs) have the potential to produce therapeutic benefits in prostate cancer, as found in two landmark randomized controlled trials which demonstrated an advantage in the primary prevention of prostate cancer. ${ }^{84,85}$

Finasteride (5 mg) compared to placebo decreases the risk of prostate cancer by $24.8 \%(\mathrm{P}<0.001)$, as found in the large, multicenter, randomized, double blind clinical Prostate Cancer Prevention Trial (PCPT) in the prevention of adenocarcinoma of the prostate. ${ }^{86}$ The 7 year trial was conducted in 18,882 men over the age of 55 years who had a normal digital rectal examination and had a PSA of $3.0 \mathrm{ng} / \mathrm{mL}$ or lower. However, along with this positive response, men in the finasteride group also had a $25.5 \%$ increased incidence of higher Gleason grade cancer. The Authors explained that this was the result of PSAdriven ascertainment bias, the clinical significance of which has been much debated.

Dutasteride was found to reduce the risk of biopsy-detectable prostate cancer by $22.8 \%$ compared to a placebo group in the Reduction by Dutasteride of Prostate Cancer Events (REDUCE) trial involving 8000 men, but concerns remained about the drug's effectiveness. ${ }^{87}$ The American Society of Clinical Oncology and the American Urological Association issued a joint guideline in 2008 recommending consideration of 5-ARIs for prostate cancer prevention. ${ }^{88}$

To delay progression to clinically significant disease, secondary prevention trials involving these agents have been conducted. In one such randomized placebo-controlled trial, dutasteride was found to reduce the time to therapeutic or pathological progression by $38.9 \%$ in men with very low-risk prostate cancer treated with active surveillance with or without dutasteride. ${ }^{89}$

Schroder et al. conducted a randomized controlled study to evaluate the effect of dutasteride in delaying PSA progression in 294 patients with biochemical failure after definitive radical prostatectomy or radiation therapy. ${ }^{90} 0$ f the 187 patients who completed the 24 -month treatment, a $66.1 \%$ reduction in relative risk was found in patients on dutasteride with a significant delay in time to PSA doubling compared with those who received placebo once daily. However, the duration of the study was not sufficient to evaluate the impact on overall survival or delay in bone metastases.

In metastatic prostate cancer, the beneficial effects of 5-ARIs have been suggested in small-scale studies. A randomized controlled study is ongoing to evaluate the effects of an antiandrogen and dutasteride in patients with hormone-resistant prostate cancer. ${ }^{91}$ The beneficial effects of $5 \alpha \mathrm{R}$ inhibition seen in these studies directed the recent interest toward combing androgen receptor targeted therapy in conjunction with other pathways such as LHRH agonists. ${ }^{92}$ 


\section{Advances in hormonal therapy: from clinical trials to clinical practice}

Metastatic prostate cancer ultimately becomes unresponsive to the standard androgen deprivation therapy presently available. A huge amount of research is being carried out to develop new therapeutic agents that can slow the progression of hormone-resistant prostate cancer (HRPC). The introduction of new androgen affecting pathways in recent clinical trials demonstrated improved survival in this setting.

The biosynthesis of the testosterone precursors dehydroepiandrosterone and androstenedione are mediated by the CYP17 enzyme. Since inhibition of this enzyme is a critical step in the prevention of biosynthesis of androgens, CYP17 inhibitors are the newest agents in the hormonal therapy for prostate cancer. ${ }^{93}$ Although ketoconazole is the first drug to be used as CYP17 inhibitor, it is non-specific and has a higher side-effect profile. ${ }^{94}$ Due to selective and irreversible inhibition of the CYP17 enzyme (17 $\alpha$-hydroxylase and C17, 20-lyase) by abiraterone acetate, this drug had significant effects in phase I/II clinical trials against prostate cancer. ${ }^{95-97}$

A large multicenter phase III trial was conducted in docetaxel-refractory 1195 patients who either receive abiraterone acetate plus prednisone or prednisone alone after randomization in a ratio of $2: 1 .^{98}$ The results were highly in favor of abiraterone acetate in terms of overall survival regardless of risk factors such as performance status, sites of metastatic disease, and number of prior chemotherapy regimens received compared to placebo ( 14.8 vs 10.9 months; $\mathrm{P}<0.001)$. Even abiraterone acetate was found to be superior with regards to all secondary end points. There were significantly less side effects with fluid retention and hypokalemia commonly seen. Abiraterone acetate reduced the levels of serum testosterone levels to $1-2 \mathrm{ng} / \mathrm{dL}$; this is much lower than the previous standard of $50 \mathrm{ng} / \mathrm{dL}$ seen with previous hormonal drugs.

In addition, a phase III clinical trial (NCT887198) was recently conducted to explore the role of abiraterone acetate in $1088 \mathrm{HRPC}$ patients who had not been previously treated with docetaxel. The results demonstrated that abiraterone acetate produced a significant improvement in OS, progression-free survival, and time to chemotherapy initiation. ${ }^{99}$

Another non-steroidal CYP17 inhibitor currently being investigated in phase III clinical trials in both chemotherapy-refractory and naive patients is TAK-700. In contrast to abiraterone acetate, TAK-700 is a reversible inhibitor of CYP-17 and inhibits only C17, 20-lyase. ${ }^{100-102}$ In a phase I/II trial, $41-63 \%$ of patients showed a $50 \%$ or more decrease in PSA with TAK-700 at 12 weeks. ${ }^{103}$ Fatigue, nausea and constipation were the most common adverse effects. Further clinical trials of TAK700 are currently ongoing. ${ }^{104}$ More recently, a phase I/I clinical trial ${ }^{105}$ evaluated TOK-001 (Galeterone®) as another important CYP17 inhibitor. Uniquely, TOK-001 is also an androgen receptor modulator in addition to the selective CYP17 inhibitor. ${ }^{106}$ The main drawback of the currently available antiandrogens is that they do not completely block androgen receptor signaling. ${ }^{107} \mathrm{MDV} 3100$ is a new generation antiandrogen having pure androgen receptor antagonist activity without agonist activity, thus, more effectively blocking the androgen receptor nuclear translocation activity. ${ }^{108}$

In a multicenter phase I/II study involving 140 patients, Scher $e t$ al. reported a favorable response of MDV3100 with a decrease in serum PSA of $50 \%$ or more in $56 \%$ of patients, soft tissue response in $22 \%$ patients and bone disease remaining stable in $56 \%$ patients. ${ }^{109}$ Fatigue and seizure at higher doses were the side-effects observed. ${ }^{109,110}$ Further phase III trials evaluating the role of MDV3100 before docetaxel chemotherapy in men with CRPC are ongoing. ${ }^{111}$

Enzalutamide is another orally bio-available androgen receptor antagonist (FDA approved in 2012) that has been demonstrated to reduce both AR translocation and interaction with coactivators. ${ }^{108}$ In an AFFIRM phase III trial, 1199 men were randomized to receive either enzalutamide or placebo in patients who already received docetaxelbased chemotherapy. Significant beneficial effects were seen with enzalutamide in patient OS (median 18.4 months vs 13.6 months; $\mathrm{P}<0.001)^{112,113}$ and in secondary end points of PSA regression. Fatigue, diarrhea, musculoskeletal pain, and hot flashes were the mild sideeffects observed during the study. The efficacy of this drug is now being evaluated in an ongoing phase III PREVAIL trail in pre-docetaxel settings (NCT1212991). Lastly, ARN-509, another antiandrogen, is currently under clinical development and was found to be more efficacious in animal models. ${ }^{114}$ This drug is being evaluated in enzalutamideresistant cases.

\section{Conclusions}

The central issue in the management of patients with metastatic prostate cancer is the appropriate balance between effective palliation and acceptable toxicity. Despite several refinements and modifications in the management protocol, no significant improvement in survival benefit has been demonstrated for metastatic prostate cancer and the optimal management of these patients still has to be defined. Use of hormonal therapy will not cure the disease and ultimately all men will develop the cancer that is refractory to hormonal manipulations. With the introduction of various new hormonal agents, the treatment paradigm of castration-resistant prostate cancer is changing dramatically. Fresh controversy about optimal timing and the correct sequence of use of these recently developed hormonal agents may arise in the near future. This means that these present issues concerning hormonal therapy serve to confirm the clear and continuous need to further refine available hormonal therapy, as well as to develop new more effective agents. New guidelines are urgently required to provide optimal treatment for advanced stage prostate cancer.

\section{References}

1. Huggins C, Hodges CV. Studies on prostatic cancer II: the effects of castration on advanced carcinoma of the prostate gland. Arch Surg 1941;43:209-23.

2. Trachtenberg J. Hormonal management of stage D carcinoma of the prostate. In: Carson CC, ed. Problems in urology. Vol. 7. Philadelphia: JB Lippincott Co; 1993. pp 215-25.

3. Gomella LG, Johannes J, Trabulsi EJ. Current prostate cancer treatments: effect on quality of life. Urology 2009;73:S28-35.

4. Schwandt A, Garcia JA. Complications of androgen deprivation therapy in prostate cancer. Curr Opin Urol 2009;19:322-6.

5. Aus G, Abbou CC, Bolla M, et al. EAU guidelines on prostate cancer. Up-dated full version; March 2005. Available from: http://www. uroweb.org

6. Bayraktar S, Wahab MA. Current medical and surgical options for androgen deprivation in prostate cancer patients. Open Prostate Cancer J 2010;3:39-46.

7. Kolvenbag GJ, Iversen P, Newling DW. Antiandrogen monotherapy: a new form of treatment for patients with prostate cancer. Urol Rev 200;58:16-23.

8. The Veterans Administration Co-operative Urological Research Group. Treatment and survival of patients with cancer of the prostate. Surg Gynecol Obstet 1967;124:1011-17.

9. Jordan WP Jr, Blackard CE, Byar DP. Reconsideration of orchidectomy in the treatment of advanced prostatic carcinoma. South Med 


\section{J 1977;70:1411-3.}

10. Byar DP, Corle DK. Hormone therapy for prostate cancer: results of the Veterans Administration Cooperative Urological Research Group studies. NCI Monogr 1988:165-70.

11. Byar DP. The Veterans Administration Cooperative Urological Research Group's studies of cancer of the prostate. Cancer 1973;32:1126-30.

12. Clark JA, Wray NP, Ashton CM. Living with treatment decisions: regrets and quality of life among men treated for metastatic prostate cancer. J Clin Oncol 2001;19:72-80.

13. Chadwick DJ, Gillatt DA, Gingell JC. Medical or surgical orchiectomy: the patients' choice. BMJ 1991;302:572.

14. Boccon-Gibod L. Optimising hormone therapy in advanced disease. Eur Urol Suppl 2005;4:21-9.

15. Seidenfeld J, Samson DJ, Hasselblad V, et al. Single-therapy an-drogen suppression in men with advanced prostate cancer: a systematic review and meta-analysis. Ann Intern Med 2000;132:566-77.

16. Scherr D, Pitts WR, Vaughn ED. Diethylstilbesterol revisited: androgen deprivation, osteoporosis and prostate cancer. J Urol 2002;167:535-38.

17. Tombal B, Berges R. How good do current LHRH agonists control testosterone? Can this be improved with Eligard? Eur Urol Suppl 2005;4:30-6.

18. Zlotta A, Debruyne FMJ. Expert opinion on optimal testosterone control in prostate cancer. Eur Urol Suppl 2005;4:37-41.

19. Loblaw DA, Virgo KS, Nam R, et al. Initial hormonal management of androgen-sensitive metastatic, recurrent, or progressive prostate cancer: 2006 update of an American Society of Clinical Oncology practice guideline. J Clin Oncol 2007;25:1596-605.

20. Prostate Cancer V.2.2009. National Comprehensive Cancer Network Web site. Available from: http:/www.nccn.org/professionals/physician_gls/PDF/prostate.pdf

21. Mottet N, Bellmunt J, Bolla M, et al. [EAU guidelines on prostate cancer. Part II: treatment of advanced, relapsing, and castrationresistant prostate cancer.] Actas Urol Esp 2011;35:565-79. [Article in Spanish].

22. McLeod DG. Hormonal therapy: historical perspective to future directions. Urology 2003;61:3-74.

23. Tomera K, Gleason D, Gittelman M, et al. The gonadotropin-releasing hormone antagonist abarelix depot versus luteinizing hormone releasing hormone agonists leuprolide or goserelin: initial results of endocrinological and biochemical efficacies in patients with prostate cancer. J Urol 2001;165:1585-9.

24. Klotz L, Boccon-Gibod L, Shore ND, et al. The efficacy and safety of degarelix: a 12-month, comparative, randomized, open-label, parallel-group phase III study in patients with prostate cancer. BJU Int 2008;102:1531-8.

25. McLeod D, Zinner N, Tomera K, et al. A phase 3, multicenter, openlabel, randomized study of abarelix versus leuprolide acetate in men with prostate cancer. Urology 2001;58:756-61.

26. Trachtenberg J, Gittleman M, Steidle C, et al. A phase 3, multicenter, open label, randomized study of abarelix versus leuprolide plus daily antiandrogen in men with prostate cancer. J Urol 2002;167:1670-4.

27. Selvaggi F, Khoe GSS, Van Cangh P, et al. Comparison of abarelix depot (A-D) and goserelin (G) plus bicalutamide (B) in advanced prostate cancer: results of a multicentre, open-label, randomised, phase III study. Eur Urol 2001;39:78.

28. Debruyne F, Bhat G, Garnick MB. Abarelix for injectable suspension: first-in-class gonadotropin-releasing hormone antagonist for prostate cancer. Future Oncol 2006;2:677-96.

29. Mongiat-Artus P, Teillac P. Abarelix: the first gonadotrophin-releasing hormone antagonist for the treatment of prostate cancer. Expert Opin Pharmacother 2004;5:2171-9.
30. Huhtaniemi I, White R, McArdle CA, Persson BE. Will GnRH antagonists improve prostate cancer treatment? Trends Endocrinol Metab 2009;20:43-50.

31. Barmoshe S, Zlotta AR. Pharmacotherapy for prostate cancer, with emphasis on hormonal treatments. Expert Opin Pharmacother 2006;7:1685-99.

32. Shore ND, Abrahamsson PA, Anderson J, et al. New considerations for ADT in advanced prostate cancer and the emerging role of GnRH antagonists. Prostate Cancer Prostatic Dis 2013;16:7-15.

33. Omabe M, Ezeani M, Onyekachi OB. Androgen ablation therapy and prostate cancer: an update. BJM Med Res 2013;3:1034-49.

34. Gomella LG. Effective testosterone suppression for prostate cancer: is there a best castration therapy? Rev Urol 2009;11:52-60.

35. Smith MR, Goode M, Zietman AL, et al. Bicalutamide monotherapy versus leuprolide monotherapy for prostate cancer: effects on bone mineral density and body composition. J Clin Oncol 2004;22:2546-53.

36. Sieber PR, Keiller DL, Kahnoski RJ, et al. Bicalutamide $150 \mathrm{mg}$ maintains bone mineral density during monotherapy for localized or locally advanced prostate cancer. J Urol 2004;171:2272-6.

37. Wirth M, Tyrrell C, Delaere K, et al. Bicalutamide ('Casodex') 150 $\mathrm{mg}$ in addition to standard care in patients with nonmetastatic prostate cancer: updated results from a randomised double-blind phase III study (median followup $5.1 \mathrm{y}$ ) in the early prostate cancer programme. Prostate Cancer Prostatic Dis 2005;8:194-200.

38. d'Ancona FC, Debruyne FM. Endocrine approaches in the therapy of prostate carcinoma. Hum Reprod Update 2005;11:309-17.

39. Anderson J. The role of antiandrogen monotherapy in the treatment of prostate cancer. BJU Int 2003;91:455-61.

40. Wirth MP, Hakenberg OW, Froehner M. Antiandrogens in the treatment of prostate cancer. Eur Urol 2007;51:306-13.

41. de Voogt HJ. The position of cyproterone acetate (CPA), a steroidal anti-androgen, in the treatment of prostate cancer. Prostate 1992:91-5.

42. Iversen P. Antiandrogen monotherapy: indications and results. Urology 2002;60:64-71.

43. Sharifi N, Gulley JL, Dahut WL. Androgen deprivation therapy for prostate cancer. JAMA 2005;294:238-44.

44. Schröder FH, Whelan P, de Reijke TM, et al. Metastatic prostate cancer treated by flutamide versus cyproterone acetate. Final analysis of the "European Organization for Research and Treatment of Cancer" (EORTC) Protocol 30892. Eur Urol 2004;45:457-64.

45. Boccardo F. Hormone therapy of prostate cancer: Is there a role for antiandrogen monotherapy? Crit Rev Oncol Hematol 2000;35:12132.

46. Chang A, Yeap B, Davis T, et al. Double-blind, randomized study of primary hormonal treatment of stage D2 prostate carcinoma: Flutamide versus diethylstilbestrol. J Clin Oncol 1996;14:2250-7.

47. Decensi AU, Boccardo F, Guarneri D, et al. Monotherapy with nilutamide, a pure nonsteroidal antiandrogen, in untreated patients with metastatic carcinoma of the prostate. J Urol 1991;146:377-81.

48. Dole EJ, Holdsworth MT. Nilutamide: An antiandrogen for the treatment of prostate cancer. Ann Pharmacother 1997;31:65-75.

49. McLeod DG. Tolerability of nonsteroidal antiandrogens in the treatment of advanced prostate cancer. Oncologist 1997;2:18-27.

50. Bales GT, ChodakGW. Acontrolled trial of bicalutamide versus castration in patients with advanced prostate cancer. Urology 1996;47:38-43.

51. Tyrrell CJ, Kaisary AV, Iversen $P$, et al. A randomized comparison of 'Casodex'TM (bicalutamide) $150 \mathrm{mg}$ monotherapy versus castration in the treatment of metastatic and locally advanced prostate cancer. Eur Urol 1998;33:447-56.

52. Iversen P, Tyrrell CJ, Kaisary AV, et al. Bicalutamide monotherapy 
compared with castration in patients with nonmetastatic locally advanced prostate cancer: 6.3 years of followup. J Urol 2000;164:1579-82.

53. Schröder FH. Antiandrogens as monotherapy for prostate cancer. Eur Urol 1998;34:12-7.

54. Kaisary AV, Iversen P, Tyrrell CJ, et al. Is there a role for antiandrogen monotherapy in patients with metastatic prostate cancer? Prostate Cancer Prostatic Dis 1999;4:196-203.

55. Klotz L, Toren P. Androgen deprivation therapy in advanced prostate cancer: is intermittent therapy the new standard of care? Curr Oncol 2012;19:S13-S21.

56. Tunn U. The current status of intermittent androgen deprivation (IAD) therapy for prostate cancer: putting IAD under the spotlight. BJU Int 2007;99:19-22.

57. Miller K, Steiner U, Lingnau A, et al. Randomised prospective study of intermittent versus continuous androgen suppression in advanced prostate cancer. J Clin Oncol 2007;25:5015.

58. Langenhuijsen J, Schasfoort E, Heathcote P, et al. Intermittent androgen suppression in patients with advanced prostate cancer: an update of the TULP survival data. Eur Urol 2008;7:205.

59. Calais da Silva FE, Bono AV, et al. Intermittent androgen deprivation for locally advanced and metastatic prostate cancer: results from a randomised phase 3 study of the South European Uroncological Group. Eur Urol 2009;55:1269-77.

60. Sandford NL, Searle JW, Kerr JF. Successive waves of apoptosis in the rat prostate after repeated withdrawal of testosterone stimulation. Pathology 1984;16:406-10.

61. Crook JM, O'Callaghan CJ, Duncan G, et al. Intermittent androgen suppression for rising psa level after radiotherapy. N Engl J Med 2012;367:895-903.

62. Hussain M, Tangen CM, Higano CS, et al. Intermittent (iad) versus continuous androgen deprivation (cad) in hormone sensitive metastatic prostate cancer (hsmlpc) patients (pts): results of S9346 (int-0162), an international phase iii trial. J Clin Oncol 2012:30.

63. Heidenreich A, Bastian PJ, Bellmunt J, et al. Guidelines on prostate cancer. 2012; Available from: http://www.uroweb.org/ gls/pdf/08\%20 Prostate\%20Cancer_LR\%20March\%2013th\%202012.pdf

64. NICE. Prostate Cancer: Diagnosis and Treatment 2008. Available from: http://www.nice.org.uk/nicemedia/live/11924/39687/39687.pdf

65. American Urological Association. Guideline for the management of clinically localized prostate cancer: 2007 update. Linthicum, MD: American Urological Association; 2007.

66 . Niraula S, Tannock IF. Broadening horizons in medical management of prostate cancer. Acta Oncol 2011;50:141-7.

67. Chodak GW. A critical review of maximal androgen blockade for advanced prostate cancer. Rev Urol 2004;6:S18-23.

68. Crawford ED, Eisenberger MA, McLeod DG, et al. A controlled trial of leuprolide with and without flutamide in prostatic carcinoma. $\mathrm{N}$ Engl J Med 1989;321:419-24.

69. Denis LJ, Carnelro de Moura JL, Bono A, et al. Goserelin acetate and flutamide versus bilateral orchiectomy: a phase III EORTC trial (30853). EORTC GU Group and EORTC Data Center. Urology 1993;42:119-30.

70. Janknegt RA, Abbou CC, Bartoletti R, et al. Orchiectomy and nilutamide or placebo as treatment of metastatic prostatic cancer in a multinational double-blind randomized trial. J Urol 1993;149:77-83.

71. Maximum androgen blockade in advanced prostate cancer: an overview of the randomised trials. Prostate Cancer Trialists' Collaborative Group. Lancet 2000;355:1491-8.

72. Schmitt B,Wilt TJ, Schellhammer PF, et al. Combined androgen blockade with nonsteroidal antiandrogens for advanced prostate cancer: a systematic review. Urology 2001;57:727-32.

73. Akaza H, Yamaguchi A, Matsuda T, et al. Superior anti-tumor effi- cacy of bicalutamide $80 \mathrm{mg}$ in combination with a luteinizing hormone-releasing hormone (LHRH) agonist versus LHRH agonist monotherapy as first-line treatment for advanced prostate cancer: Interim results of a randomized study in Japanese patients. Jpn J Clin Oncol 2004;34:20-8.

74. Samson DJ, Seidenfeld J, Schmitt B, et al. Systematic review and meta-analysis of monotherapy compared with combined androgen blockade for patients with advanced prostate carcinoma. Cancer 2002;95:361-76.

75. Moinpour CM, Savage MJ, Troxel A, et al. Quality of life in advanced prostate cancer: results of a randomized therapeutic trial. J Natl Cancer Inst 1998;90:1537-44.

76. Moul JW. Twenty years of controversy surrounding combined androgen blockade for advanced prostate cancer. Cancer 2009;115:3376-8.

77. Chodak G, Gomella L, Phung de H. Combined androgen blockade in advanced prostate cancer: looking back to move forward. Clin Genitourin Cancer 2007;5:371-8.

78. Chodak GW. A critical review of maximal androgen blockade for advanced prostate cancer. Rev Urol 2004;6:S18-23.

79. Cruz Guerra NA. Outcomes from the use of maximal androgen blockade in prostate cancer at health area with reference hospital type 2 (1st part). Quality of life: application of EORTC QLQ-C30 instrument. Arch Esp Urol 2009;62:431-57.

80. Mulrow C, Langhome P, Grimshaw J. Integrating heterogeneous pieces of evidence in systematic reviews. Ann Intern Med 1997;127:989-95.

81. Cannata DH, Kirschenbaum A, Levine AC. Androgen deprivation therapy as primary treatment for prostate cancer. J Clin Endocrinol Metab 2012;97:360-5.

82. Brawer MK. Hormonal therapy for prostate cancer. Rev Urol 2006;8:S35-S47.

83. Perlmutter MA, Lepor $\mathrm{H}$. Androgen deprivation therapy in the treatment of advanced prostate cancer. Rev Urol 2007;9:S3-8.

84. Thompson IM, Goodman PJ, Tangen CM, et al. The influence of finasteride on the development of prostate cancer. $N$ Engl J Med 2003;349:215-24.

85. Andriole GL, Bostwick DG, Brawley OW, et al. Effect of dutasteride on the risk of prostate cancer. N Engl J Med 2010; 362:1192-202.

86. Thompson IM, Chi C, Ankerst DP, et al. Effect of finasteride on the sensitivity of PSA for detecting prostate cancer. J Natl Cancer Inst 2006;98:1128.

87. Andriole G, Bostwick D, Brawley 0, et al. Chemoprevention of prostate cancer in men at high risk: rationale and design of the Reduction by Dutasteride of Prostate Cancer Events (REDUCE) trial. J Urol 2004;172:1314.

88. Kramer BS, Hagerty KL, Justman S, et al. Use of 5-alpha-reductase inhibitors for prostate cancer chemoprevention: American Society of Clinical Oncology/American Urological Association 2008 Clinical Practice Guideline. Clin Oncol 27:1502-16.

89. Fleshner NE, Lucia MS, Egerdie B, et al. Dutasteride in localised prostate cancer management: the REDEEM randomised, doubleblind, placebo-controlled trial. Lancet 2012;379:1103-11.

90. Schroeder F, Bangma C, Angulo JC, et al. Dutasteride treatment over 2 years delays prostate-specific antigen progression in patients with biochemical failure after radical therapy for prostate cancer: results from the randomised, placebo-controlled Avodart After Radical Therapy for Prostate Cancer Study (ARTS). Eur Urol 2013;63:779-87.

91. Sartor 0, Gomella LG, Gagnier P, et al. Dutasteride and bicalutamide in patients with hormone-refractory prostate cancer: the Therapy Assessed by Rising PSA (TARP) study rationale and design. Can J Urol 2009;16:4806-12.

92. Singh P, Uzgare A, Litvinov I, et al. Combinatorial androgen recep- 
tor targeted therapy for prostate cancer. Endocr Relat Cancer 2006;13:653.

93. Xiaoyu H, Thomas WF. Redefining hormone sensitive disease in advanced prostate cancer. Adv Urol 2012;2012:978531.

94. Vasaitis TS, Bruno RD, Njar VC. CYP17 inhibitors for prostate cancer therapy. J Steroid Biochem Mol Biol 2010;125:23-31.

95. Reid AH, Attard G, Barrie E, de Bono JS. CYP17 inhibition as a hormonal strategy for prostate cancer. Nat Clin Pract Urol 2008;5:61020.

96. Attard G, Reid AHM, A'Hern R, et al. Selective inhibition of CYP17 with abiraterone acetate is highly active in the treatment of castration-resistant prostate cancer. J Clin Oncol 2009;27:3742-8.

97. Reid AH, Attard G, Danila D, et al. Significant and sustained antitumor activity in post-docetaxel, castration-resistant prostate cancer with the CYP17 inhibitor abiraterone acetate. J Clin Oncol 2010;28:1489-95.

98. de Bono JS, Logothetis CJ, Molina A, et al. Abiraterone and increased survival in metastatic prostate cancer. New Engl J Med 2011;364:1995-2005.

99. Fizazi K, Carducci M, Smith M, et al. Denosumab versus zoledronic acid for treatment of bone metastases in men with castrationresistant prostate cancer: a randomised, doubleblind study. Lancet 2011;377:813-22.

100.Ryan CJ, Smith MR, Fong L, et al. Phase I clinical trial of the CYP17 inhibitor abiraterone acetate demonstrating clinical activity in patients with castration-resistant prostate cancer who received prior ketoconazole therapy. J Clin Oncol 2010;28:1481-8.

101.Jarman M, Barrie SE, Liera JM. The 16,17-double bond is needed for irreversible inhibition of human cytochrome P45017 $\alpha$ by abiraterone (17-(3-Pyridyl)androsta-5,16-dien-3 $\beta$-ol) and related steroidal inhibitors. J Medicinal Chem 1998;41:5375-81.

102.Hara T, Kouno J, Kaku T, et al. Effect of a novel 17,20-lyase inhibitor, orteronel (TAK-700), on androgen synthesis in male rats. J Steroid Biochem Mol Biol 2013;134:80-91.

103.Agus DB, Stadler W, Shevrin DH, et al.Safety, efficacy, and pharmacodynamics of the investigational agent TAK-700 in metastatic cas- tration-resistant prostate cancer (mCRPC): updated data from a phase I/II study. J Clin Oncol 2011;29:abstract 4531.

104.Tolcher AW, Chi KN, Shore ND, et al. Effect of abiraterone acetate plus prednisone on the QT interval in patients with metastatic castration-resistant prostate cancer. Cancer Chemother Pharmacol 2012;70:305-13.

105.Vasaitis TS, Bruno RD, Njar VC. CYP17 inhibitors for prostate cancer therapy. J Steroid Biochem Mol Biol 2011;125:23-31.

106. Molina A, Belldegrun A. Novel therapeutic strategies for castration resistant prostate cancer: inhibition of persistent androgen production and androgen receptor mediated signaling. J Urol 2011;185:787-94.

107. Chen Y, Sawyers CL, Scher HI. Targeting the androgen receptor pathway in prostate cancer. Curr Opin Pharmacol 2008;8:440-8.

108.Tran C, Ouk S, Clegg NJ, et al. Development of a secondgeneration antiandrogen for treatment of advanced prostate cancer. Science 2009;324:787-90.

109.Scher HI, Beer TM, Higano CS, et al. Antitumour activity ofMDV3100 in castration-resistant prostate cancer: a phase 1-2 study. Lancet 2010;375:1437-46.

110. Foster WR, Car BD, Shi H, et al. Drug safety is a barrier to the discovery and development of new androgen receptor antagonists. Prostate 2011;71:480-8.

111.Massard C, Fizazi K. Targeting continued androgen receptor signaling in prostate cancer. Clin Cancer Res 2011;17:3876-83.

112.Scher HI, Fizazi K, Saad F, et al. Increased survival with enzalutamide in prostate cancer after chemotherapy. N Engl $\mathrm{J}$ Med 2012;367:1187-97.

113.Scher HI, Fizazi K, Saad F, et al. Effect of MDV3100, an androgen receptor signaling inhibitor (ARSI), on overall survival in patients with prostate cancer postdocetaxel: results fromthe phase III AFFIRM study. J Clin Oncol 2012;30:abstract LBA1.

114.Clegg NJ, Wongvipat J, Joseph JD, et al. ARN-509: a novel antiandrogen for prostate cancer treatment. Cancer Res 2012;72:1494503. 